\title{
YET TWO ADDITIONAL LARGE NUMBERS OF SUBUNIVERSES OF FINITE LATTICES
}

\author{
Delbrin Ahmed And Eszter K. Horváth \\ University of Szeged, Bolyai Institute \\ e-mail: Delbrin@math.u-szeged.hu \\ horeszt@math.u-szeged.hu
}

\begin{abstract}
By a subuniverse, we mean a sublattice or the emptyset. We prove that the fourth largest number of subuniverses of an $n$-element lattice is $43 \cdot 2^{n-6}$ for $n \geq 6$, and the fifth largest number of subuniverses of an $n$-element lattice is $85 \cdot 2^{n-7}$ for $n \geq 7$. Also, we describe the $n$-element lattices with exactly $43 \cdot 2^{n-6}$ (for $n \geq 6$ ) and $85 \cdot 2^{n-7}$ (for $n \geq 7$ ) subuniverses.
\end{abstract}

Keywords: finite lattice, sublattice, number of sublattices, subuniverse.

2010 Mathematics Subject Classification: Primary: 06B99; Secondary: 08A30.

\section{REFERENCES}

[1] G. Czédli, A note on finite lattices with many congruences, Acta Universitatis Matthiae Belii, Series Mathematics Online (2018) 22-28.

http://actamath.savbb.sk/pdf/oacta2018003.pdf

[2] G. Czédli, Lattices with many congruences are planar, Algebra Universalis (2019) $80: 16$

doi:10.1007/s00012-019-0589-1

[3] G. Czédli, Eighty-three sublattices and planarity.

http://arxiv.org/abs/1807.08384

[4] G. Czédli, Finite semilattices with many congruences, (Order). doi:10.1007/s11083-018-9464-5

[5] G. Czédli and E.K. Horváth, A note on lattices with many sublattices. https://arxiv.org/abs/1812.11512

[6] G. Grätzer, Lattice Theory: Foundation (Birkhäuser Verlag, Basel, 2011). doi:10.1007/978-3-0348-0018-1 
[7] I. Rival and R. Wille, Lattices freely generated by partially ordered sets: which can be "drawn"?, J. Reine Angew. Math. 310 (1979) 56-80.

doi: $10.1515 /$ crll.1979.310.56

Received 15 March 2019

Revised 9 June 2019

Accepted 2 July 2019 